\title{
Endogenous Separation, Wage Rigidity and the Dynamics of Unemployment*
}

\author{
Daniel L. Tortorice ${ }^{\dagger}$ \\ Brandeis University
}

September 2010

\begin{abstract}
This paper shows that the Mortensen-Pissarides (MP) model requires endogenous separation to explain the volatility of unemployment. I estimate a version of the MP model with wage rigidity and permanent shocks to match productivity. The model generates sufficient volatility in unemployment, vacancies, job-finding and job-separation despite relatively low worker outside options. I then re-estimate the model while restricting the separation rate to be constant and show that, even though the estimation procedure finds the best fitting model, the model predicts too little variance in unemployment and too much variance in the job-finding rate. Based on this result I conclude that models of unemployment fluctuations need endogenous separation rates to explain unemployment fluctuations.
\end{abstract}

Keywords: Unemployment, Search Models, Business Cycles JEL Codes: J64, E24, E32

${ }^{*}$ I thank David Laibson, N. Gregory Mankiw, and James Stock for advising me on this project. I also thank Bruce Fallick, Andrew Figura, Kirk Moore, Gauri Kartini Shastry and participants in seminars at Harvard University, Brandeis University, the Federal Deposit Insurance Corporation, The Federal Reserve Board of Governors and the University of Notre Dame for helpful comments and suggestions. I thank Harvard University and the United States Department of Education, Jacob K. Javits Fellowship Program for supporting my graduate education. All mistakes are mine. A previous version of this paper was titled "Separation Rate Volatility and the Value of Work"

${ }^{\dagger}$ Brandeis University, Department of Economics. Email: tortoric@brandeis.edu. Phone: 617-501-8584 


\section{Introduction}

The Mortensen \& Pissarides (1994) (MP) search and matching model is the dominant paradigm for studying unemployment fluctuations. Shimer (2005b) argues that the separation rate is relatively acyclical and contributes little to unemployment fluctuations. He advocates versions of the MP model that explain unemployment fluctuations primarily with movements in the job-finding rate. Recent work (e.g. Hall (2005a), Gertler \& Trigari (2006)) follows Shimer's reasoning and attempts to explain unemployment fluctuations with a constant separation rate. These papers suggest the MP model does not need endogenous separation to explain unemployment fluctuations. Instead, this strand of the literature aims to explain unemployment fluctuations by using wage rigidity to amplify the response of the job-finding rate to changes in productivity.

However, recent empirical papers dispute Shimer's claim of an acyclical separation rate. As Elsby et al. (2007) conclude, "A complete understanding of cyclical unemployment requires an explanation of countercyclical inflow rates." Noting this evidence, another strand of the literature (e.g. Ramey (2008) and Menzio \& Shi (2009)) focuses on modeling endogenous separation. However these models suffer from the Shimer puzzle (Shimer (2005a)) i.e. they generates too little variance in the job finding rate.

Both strands of the literature are important contributions to our understanding of unemployment fluctuations. However, since both strands underestimate the importance of one channel in generating unemployment fluctuations (either job-finding or job-separation) neither can fully evaluate the importance of job-separation in contributing to unemployment fluctuations. My paper bridges the gap between these two approaches. I estimate a version of the MP model with endogenous separation and wage rigidity. I estimate the model using the Generalized Method of Moments (GMM). The model is consistent with the observed levels of unemployment, vacancy, and job-finding and separation rate volatility as well as the signs of all the correlation coefficients. Importantly, the presence of wage rigidity allows the model to match the Beveridge curve (the negative correlation between vacancies and 
unemployment) even with variation in the separation rate.

This paper then can evaluate the Hall (2005b) and Shimer (2005b) claim that models of unemployment fluctuations do not need variation in the job-separation rate to explain the volatility of unemployment. It answers the question: Do models of unemployment fluctuations need variation in the separation rate? I find that the answer is yes. I re-estimate a version of the model with a constant separation rate and show that the overall fit of the model is much poorer. Since I use GMM to estimate the constant separation rate model, I show that the best fitting constant separation rate model, found by searching over the entire parameter space, will predict too little variation in unemployment and too much variation in the job-finding rate. This result is the main contribution of the paper. I do not propose a new solution to the Shimer puzzle, but use existing explanations (i.e. wage rigidity) to elucidate the importance of separation rate fluctuations in explaining unemployment volatility.

The papers in the literature closest to mine are Ramey (2008) and Menzio \& Shi (2009). Both papers point out that the Mortensen-Pissarides model fails to generate sufficient unemployment volatility without an endogenous separation rate. My paper differs from their work for two reasons. Firstly, I allow for wage rigidity in the model. Therefore, my model does not suffer from the Shimer puzzle, i.e. it is able to generate sufficient volatility in the job finding rate. What I do is start with a model that generates sufficient volatility in job-finding and job-separation rate. Then, I show that when job-separation is held constant the model fails to match the volatility of unemployment. The baseline models of Ramey and Menzio and Shi do not generate job-finding volatility that matches the standard deviation of the jobfinding rate seen in the data. Based on their results one wonders if a model with sufficient job-finding rate volatility could explain unemployment fluctuations without separation rate fluctuations. I show that the answer is no. Even a model that is able to generate sufficient volatility in job-finding will not generate sufficient volatility of unemployment.

Secondly, instead of calibrating the model, I estimate the model using GMM. This method allows me to show that there is no calibration of the constant separation rate model for which 
there will be sufficient unemployment volatility. In this sense, my approach is immune to the calibration critique that Hagedorn \& Manovskii (2006) level against Shimer (2005a). They argue that Shimer's results are sensitive to the choice of calibration for key parameters. Since my estimation process finds the best fitting model, I know that there is no calibration of the exogenous separation rate model that can explain the volatility of unemployment.

My paper also differs from the empirical work of Elsby et al. (2007). They show that the separation rate is counter-cyclical and contributes empirically to unemployment fluctuations. However, their work leaves open the question addressed in this paper: while the separation rate is counter-cyclical, is assuming an acyclical separation rate in theoretical models a reasonable approximation if the goal is only to explain the behavior of unemployment and vacancies? I show that the answer is no. The model needs variation in the separation rate to match unemployment, vacancy and job-finding rate moments alone.

Admittedly, the baseline model is not strikingly novel. It is a simplified version of the original MP model (only two persistent job specific productivity levels) with wage rigidity based on Hall (2005a). However, the model has several advantages. It can be linearized and estimated by GMM. I estimate the model's structural parameters, and since the model explains the key moments of the data, it can be used effectively in policy analysis. It may very well be one of the simplest models consistent with the observed volatility of unemployment, vacancies, job-finding and the job-separation rate.

Finally, note that this paper explains unemployment, job-finding and job-separation rate fluctuations assuming that worker outside options are low. (I do not use the Hagedorn \& Manovskii (2006) calibration where unemployment is almost as valuable as work.) This is the most common view in the literature. In fact, Shimer (2005a), Hall (2005a) and Gertler \& Trigari (2006) all assume that unemployment is about $40 \%$ as valuable as work. Hall \& Milgrom (2008) estimate that worker's outside options are $75 \%$ as valuable as work. Additionally, as Costain \& Reiter (2003) point out, models with a value of work near that of unemployment generate responses of unemployment to labor market policies that are much 
too large. They estimate worker outside options of $75 \%$ the value of work by matching the observed response of unemployment to labor market policies. Therefore, I assume worker outside options equal to $75 \%$ the value of work.

The rest of the paper proceeds as follows. Section two describes the baseline model with endogenous separation and wage rigidity. Section three explains the model solution and the GMM estimation and shows that this model is consistent with the observed standard deviations of unemployment, job-finding and job-separation. In section four, I demonstrate that once the separation rate is restricted to be constant, the model fits the data poorly: predicting too much variance in job-finding and too little variance in unemployment. Section five discusses the robustness of the results. Finally, section six concludes.

\section{Vulnerable Jobs Model}

\subsection{Theoretical Model}

\subsubsection{Informal Description}

In this section I describe a version of the Mortensen-Pissarides model that I call the vulnerable jobs model. It is consistent with the observed volatility of unemployment, the jobseparation rate and the job-finding rate. The model is a version of Fujita (2004) that I modify to include permanent productivity differences across matches and wage rigidity. Fujita's model is a modification of den Haan et al. (2000), omitting capital and consumption. Their model is a discrete time version of Mortensen \& Pissarides (1994) with two modifications: match specific shocks are i.i.d. and aggregate productivity follows an $\mathrm{AR}(1)$ process.

To model permanent productivity differences across matches I allow the model to have two types of jobs: a good job and a bad job. The bad job has productivity a fraction permanently lower than the productivity of the good job. Each job is also hit with an i.i.d. idiosyncratic productivity shock every period. With some exogenous probability workers 
can transition from the good job to the bad job. Workers separate from the bad job into unemployment when the value of unemployment exceeds the value of the match.

My second main departure from the MP framework if the inclusion of wage rigidity. Shimer (2005a) demonstrates that the Mortensen-Pissarides model does not generate sufficient unemployment volatility when workers' outside options are low. Finding this also to be the case for my model as well, I add wage stickiness, as in Hall (2005a), to increase the model's ability to generate unemployment volatility.

Because wages are rigid, they may be, at times, too high. If the match receives a shock below a certain threshold, the firm will want to sever the match. I assume that if the firm is hit with a shock which would lead it to fire the worker, the wage adjusts so the firm's share of the surplus is zero. This adjustment avoids an inefficient separation. I now proceed to a formal description of the model

\subsubsection{Match Productivity}

At the beginning of the period there is a mass of worker-firm matches in the good job and a mass of worker-firm matches in the bad job. Workers maximize expected discounted lifetime income. Firms maximize expected discounted profits. A fraction $\rho^{x}$ of matches exogenously separates into unemployment ${ }^{1}$. Then, a fraction $q$ of the jobs with the good technology are hit with a shock that permanently lowers their productivity to that of the bad technology. The remaining good matches have an option to produce according to the following technology $z_{i}^{g} y_{t}$ with $z_{i}^{g}$ distributed lognormal with mean 0 and variance $\sigma^{z, g}$. In addition, the workers who occupy the bad jobs can produce using the technology $\delta z_{i}^{\delta} y_{t}$ with $\delta<1$ and with $z_{i}^{\delta}$ distributed lognormal with mean 0 and variance $\sigma^{\delta}$. $y_{t}$ represents aggregate productivity, which follows the $A R(1)$ process $\ln y_{t}=\phi \ln y_{t-1}+\varepsilon_{t}$.

\footnotetext{
${ }^{1}$ Exogenous separation can be thought of as needing to leave a job for personal reasons or as receiving a permanent shock that destroys the value of the job.
} 


\subsubsection{Match Surplus and Separation}

After observing the idiosyncratic and aggregate levels of productivity, the pairs calculate the expected surplus of remaining in the match.

$$
S_{i, t}^{g}=z_{i, t}^{g} y_{t}+G_{t}^{g}-\left(U_{t}+b\right) \quad \text { and } \quad S_{i, t}^{\delta}=\delta z_{i, t}^{\delta} y_{t}+G_{t}^{\delta}-\left(U_{t}+b\right)
$$

$G_{t}^{g}$ represents the expected future discounted value to the firm and the worker if they remain in the good match today, $G_{t}^{\delta}$ is the analog for the bad match. $U_{t}$ represents the future benefits that will accrue to the worker if she is unemployed this period, and $b$ represents the flow value of being unemployed. Note that the surplus is the value of the match in excess of the worker's outside option, the value of unemployment. The firm's outside option is normalized to zero.

There is a threshold value of idiosyncratic productivity below which the surplus is zero and the match is terminated:

$$
0=z_{t}^{*, g} y_{t}+G_{t}^{g}-\left(U_{t}+b\right) \quad \text { and } \quad 0=\delta z_{t}^{*, \delta} y_{t}+G_{t}^{\delta}-\left(U_{t}+b\right)
$$

Consequently the jobs have different separation rates given by:

$$
\rho_{t}^{n, g}=\int_{0}^{z_{i t}^{*, g}} d H\left(z_{i}^{g}\right) \text { and } \rho_{t}^{n, \delta}=\int_{0}^{z_{i t}^{*, \delta}} d H\left(z_{i}^{\delta}\right)
$$

Here the separation rate is the probability of getting a shock below the zero surplus value threshold.

Letting $n_{t}^{g}$ denote the fraction of the labor force who begin the period employed in a good job and $n_{t}^{\delta}$ the fraction who begin the period employed in a bad job, the overall separation rate is equal to the exogenous separation rate plus a weighted average of two endogenous separation rates.

$$
\rho^{x}+\left(1-\rho^{x}\right)\left(\frac{(1-q) n_{t}^{g}}{n_{t}^{g}+n_{t}^{\delta}} \rho_{t}^{g, n}+\frac{n_{t}^{\delta}+q n_{t}^{g}}{n_{t}^{g}+n_{t}^{\delta}} \rho_{t}^{\delta, n}\right)
$$


To interpret this formula, note that before separation occurs a fraction $q$ of the good matches become bad matches. When endogenous separation occurs there are $(1-q) n_{t}^{g}$ good matches and $n_{t}^{\delta}+q n_{t}^{g}$ bad matches.

\subsubsection{Wage Setting}

The standard MP model assumes that wages are perfectly flexible and adjust so that the firm gets a share $\pi$ of the surplus. In this model I take the approach of Hall (2005a) and assume that wages are not perfectly flexible. Instead, wages are a weighted average between the wage that would give the firm a share $\pi$ of the surplus and a wage norm. This assumption allows the share of the surplus going to the firm to vary over time. After a negative productivity shock, the wage does not adjust fully downward and the firm gets a share smaller than $\pi$ of the surplus. This reduces their incentive to recruit and lowers the job-finding rate. This mechanism can generate additional volatility in job-finding. Wages then are given by:

$$
\begin{aligned}
& w_{t}^{g}\left(z_{i}\right)=\lambda \bar{w}_{t}+(1-\lambda)\left((1-\pi) z_{i} y_{t}+\pi b+F_{t}^{g}-\pi\left(G_{t}^{g}-U_{t}\right)\right) \\
& w_{t}^{\delta}\left(z_{i}\right)=\lambda \bar{w}_{t}+(1-\lambda)\left((1-\pi) \delta z_{i} y_{t}+\pi b+F_{t}^{\delta}-\pi\left(G_{t}^{\delta}-U_{t}\right)\right)
\end{aligned}
$$

where $F_{t}^{g}$ is the future expected discounted payments that accrue to the firm from the good match. $F_{t}^{\delta}$ is the analog for the bad match. $(1-\pi) z_{i t} y_{t}+\pi b+F_{t}^{g}-\pi\left(G_{t}^{g}-U_{t}\right)$ is the wage that, when paid, would give the firm a share $\pi$ of the total surplus in the good match. The analog condition holds for the bad match. $\bar{w}_{t}$ represents a wage norm that will be defined shortly. $\lambda$ is a measure of wage stickiness. The closer $\lambda$ is to one, the more rigid are wages.

Since wages are rigid, it is possible that the idiosyncratic productivity level is low enough that the firm would want to fire the worker when there is positive value in the match. The 
thresholds at which the firm would want to fire the worker are give by:

$$
\begin{aligned}
\underline{z}_{t}^{g} y_{t}+F_{t}^{g} & =\lambda \bar{w}_{t}+(1-\lambda)\left[(1-\pi) \underline{z}_{t}^{g} y_{t}+\pi b+F_{t}^{g}-\pi\left(G_{t}^{g}-U_{t}\right)\right] \\
\delta \underline{z}_{t}^{\delta} y_{t}+F_{t}^{\delta} & =\lambda \bar{w}_{t}+(1-\lambda)\left[(1-\pi) \delta \underline{z}_{t}^{\delta} y_{t}+\pi b+F_{t}^{\delta}-\pi\left(G_{t}^{\delta}-U_{t}\right)\right]
\end{aligned}
$$

Here the value of the good match to the firm $\underline{z}_{t}^{g} y_{t}+F_{t}^{g}$ exactly equals the wage it must pay $\lambda \bar{w}_{t}+(1-\lambda)\left[(1-\pi) \underline{z}_{t}^{g} y_{t}+\pi b+F_{t}^{g}-\pi\left(G_{t}^{g}-U_{t}\right)\right]$ and the value of the bad match to the firm $\delta \underline{z}_{t}^{\delta} y_{t}+F_{t}^{\delta}$ exacly equals the wage it must pay $\lambda \bar{w}_{t}+(1-\lambda)\left[(1-\pi) \delta \underline{z}_{t}^{\delta} y_{t}+\pi b+F_{t}^{\delta}-\pi\left(G_{t}^{\delta}-U_{t}\right)\right]$.

If the firm would want to fire the worker at the wage given by the wage norm, I assume that the wage adjusts so that the firm's share of the surplus is equal to zero, i.e. the firm is indifferent between keeping or firing the worker. In this case the wage in the good job would equal $z_{i t} y_{t}+F_{t}^{g}$ and the wage in the bad job would equal $\delta z_{i t} y_{t}+F_{t}^{\delta}$.

I assume that the wage norm is the average wage in the past period. Then it satisfies:

$$
\begin{aligned}
\bar{w}_{t+1}= & \Phi^{g}\left[\int_{z_{t}^{*, g}}^{\underline{z}_{t}^{g}} z_{i t} y_{t}+F_{t}^{g} d H\left(z_{i}^{g}\right)+\int_{\underline{z}_{t}^{g}}^{\infty} w_{t}^{g}\left(z_{i t}\right) d H\left(z_{i}\right)\right] \\
& +\Phi^{\delta}\left[\int_{z_{t}^{*, \delta}}^{\underline{z}_{t}^{\delta}} \delta z_{i t} y_{t}+F_{t}^{\delta} d H\left(z_{i}^{\delta}\right)+\int_{\underline{z}_{t}^{\delta}}^{\infty} w_{t}^{\delta}\left(z_{i t}\right) d H\left(z_{i}\right)\right]
\end{aligned}
$$

where $\Phi^{g}=\frac{n_{t}^{g}(1-q)}{\left(1-\rho_{t}^{n, g}\right)(1-q) n_{t}^{g}+\left(1-\rho_{t}^{n, \delta}\right)\left(n_{t}^{\delta}+q n_{t}^{g}\right)}$ and $\Phi^{\delta}=\frac{n_{t}^{g} q+n_{t}^{\delta}}{\left(1-\rho_{t}^{n, g}\right)(1-q) n_{t}^{g}+\left(1-\rho_{t}^{n, \delta}\right)\left(n_{t}^{\delta}+q n_{t}^{g}\right)}$. Here the average wage is the weighted average of the average wage in the good job and the average wage in the bad job. The weights are given by the employment shares in each type of job. The average wage in each type of job takes into account the fact that between the efficient separation threshold and the firing threshold the wage adjusts to make the firm indifferent between keeping and firing the worker. 


\subsubsection{Continuation Value Functions}

To solve the model it is necessary to calculate the continuation values. The expected future payments of the match to the firm satisfy:

$$
\begin{aligned}
& F_{t}^{g}=\beta\left(1-\rho^{x}\right) E_{t}\left[\begin{array}{c}
(1-q) \int_{\underline{z}_{t+1}^{g}}^{\infty} z_{i} y_{t+1}-w_{t+1}^{g}\left(z_{i}\right)+F_{t+1}^{g} d H\left(z_{i}\right) \\
+q \int_{\underline{z}_{t+1}^{\delta}}^{\infty} \delta z_{i} y_{t+1}-w_{t+1}^{\delta}\left(z_{i}\right)+F_{t+1}^{\delta} d H\left(z_{i}\right)
\end{array}\right] \\
& F_{t}^{\delta}=\beta\left(1-\rho^{x}\right) E_{t}\left[\int_{\underline{z}_{t+1}^{\delta}}^{\infty} \delta z_{i} y_{t+1}-w_{t+1}^{\delta}\left(z_{i}\right)+F_{t+1}^{\delta} d H\left(z_{i}\right)\right]
\end{aligned}
$$

The firm discounts future payments at a rate $\beta$, and the match remains with probability $\left(1-\rho^{x}\right)$. If the idiosyncratic productivity shock is below $\underline{z}_{t+1}$, the firm gets zero surplus. In the region where the firm gets positive value from the match, $z_{i}>\underline{z}_{t+1}$, the match carries out production. If the match is a good match the firm collects $z_{i} y_{t+1}$, pays the worker $w_{t+1}^{g}\left(z_{i}\right)$, and the match has continuation value $F_{t+1}^{g}$ to the firm. Note that with probability $q$ a match that is good at the end of the period will become bad at the start of the next period. So in that case the firm collects $\delta z_{i} y_{t+1}$, pays the worker $w_{t+1}^{\delta}\left(z_{i}\right)$, and the match has continuation value $F_{t+1}^{\delta}$ to the firm. For the bad match, there is no probability of transitioning to a different type of match. So the firm's surplus is $\delta z_{i} y_{t+1}-w_{t+1}^{\delta}\left(z_{i}\right)+F_{t+1}^{\delta}$ with probability one.

The total expected payments from remaining in the match today which accrue to the firm and to the worker satisfy (for the good and the bad jobs respectively) are:

$$
\begin{aligned}
& G_{t}^{g}=\beta\left[\left(1-\rho^{x}\right)\left(\begin{array}{c}
(1-q) \int_{z_{t+1}^{*, g}}^{\infty} z_{i} y_{t+1}+G_{t+1}^{g}-U_{t+1}-b d H\left(z_{i}^{g}\right) \\
+q \int_{z_{t+1}^{*, \delta}}^{\infty} \delta z_{i} y_{t+1}+G_{t+1}^{\delta}-U_{t+1}-b d H\left(z_{i}^{\delta}\right)
\end{array}\right)+U_{t+1}+b\right] \\
& G_{t}^{\delta}=\beta\left[\left(1-\rho^{x}\right) \int_{z_{t+1}^{*, \delta}}^{\infty} \delta z_{i} y_{t+1}+G_{t+1}^{\delta}-U_{t+1}-b d H\left(z_{i}^{\delta}\right)+U_{t+1}+b\right]
\end{aligned}
$$

In the event that the match does not separate endogenously, when $z_{i}>z_{t+1}^{*}$, the surplus of the match is $z_{i} y_{t+1}+G_{t+1}^{g}-U_{t+1}-b$ for the good match and $\delta z_{i} y_{t+1}+G_{t+1}^{g}-U_{t+1}-b$ for 
the bad match. In any event, the worker is guaranteed her outside option $U_{t+1}+b$.

Finally, the value of unemployment is:

$$
U_{t}=\beta\left[\frac{m_{t}}{u_{t}}\left(1-\rho^{x}\right)\left(\begin{array}{c}
(1-q) \int_{z_{t+1}^{*, g}}^{z_{t+1}^{g}} \underline{E}_{t+1}^{g}\left(z_{i}\right) d H\left(z_{i}^{g}\right) \\
+(1-q) \int_{\underline{z}^{g}}^{\infty} E_{t+1}^{g}\left(z_{i}\right) d H\left(z_{i}^{g}\right) \\
+q \int_{z_{t+1}^{*} \underline{z}_{t+1}^{\delta}}^{E^{\delta}} \underline{E}_{t+1}^{\delta}\left(z_{i}\right) d H\left(z_{i}^{\delta}\right) \\
+q \int_{\underline{z}_{t+1}^{\delta}}^{\infty} E_{t+1}^{\delta}\left(z_{i}\right) d H\left(z_{i}^{\delta}\right)
\end{array}\right)+U_{t+1}+b\right]
$$

where $\underline{E}_{t+1}^{g}\left(z_{i}\right)=z_{i} y_{t+1}+G_{t+1}^{g}-U_{t+1}-b, \underline{E}_{t+1}^{\delta}\left(z_{i}\right)=\delta z_{i} y_{t+1}+G_{t+1}^{\delta}-U_{t+1}-b, E_{t+1}^{g}\left(z_{i}\right)=$ $w_{t+1}^{g}\left(z_{i}\right)+G_{t+1}^{g}-F_{t+1}^{g}-U_{t+1}-b$, and $E_{t+1}^{\delta}\left(z_{i}\right)=w_{t+1}^{\delta}\left(z_{i}\right)+G_{t+1}^{\delta}-F_{t+1}^{\delta}-U_{t+1}-b$. This formulation assumes that all matches begin as a good job and descend to the bad job with probability $q$.

The worker finds a job with probability $\frac{m_{t}}{u_{t}}$ (the number of matches per unemployed worker) and with probability $\left(1-\rho^{x}\right)$ the match does not separate exogenously. With probability $q$ the match turns out to be bad. With probability $1-q$ it stays good. In the region $\left[z_{t+1}^{*}, \underline{z}_{t+1}\right]$ the worker receives a surplus value of employment equal to the whole surplus $\underline{E}_{t+1}^{g}\left(z_{i}\right)=z_{i} y_{t+1}+G_{t+1}^{g}-U_{t+1}-b$ for the good job and $\underline{E}_{t+1}^{\delta}\left(z_{i}\right)=\delta z_{i} y_{t+1}+$ $G_{t+1}^{\delta}-U_{t+1}-b$ for the bad job. For the productivity shocks $z_{i}>\underline{z}_{t+1}$ the worker receives the wage plus the future value of the surplus that does not accrue to the firm $E_{t+1}^{g}\left(z_{i}\right)=$ $w_{t+1}^{g}\left(z_{i}\right)+G_{t+1}^{g}-F_{t+1}^{g}-U_{t+1}-b$ for the good job and $E_{t+1}^{\delta}\left(z_{i}\right)=w_{t+1}^{\delta}\left(z_{i}\right)+G_{t+1}^{\delta}-F_{t+1}^{\delta}-U_{t+1}-b$ . In all cases, the worker receives her outside option $U_{t+1}+b$.

\subsubsection{Unemployment Dynamics}

Unemployment evolves according to:

$$
u_{t}=1-\left(1-\rho^{x}\right)\left(1-\rho_{t}^{n, g}\right)(1-q) n_{t}^{g}-\left(1-\rho^{x}\right)\left(1-\rho_{t}^{n, \delta}\right)\left(n_{t}^{\delta}+q n_{t}^{g}\right)
$$


where $n_{t}^{g}$ is the stock of good jobs at the beginning of the period and $n_{t}^{\delta}$ is the stock of bad jobs at the beginning of the period. The total size of the labor force is normalized to one. The unemployed workforce is the whole labor force, 1 , minus the fraction $\left(1-\rho^{x}\right)\left(1-\rho_{t}^{n, g}\right)$ of good matches that do not separate multiplied by the number of good matches $(1-q) n_{t}^{g}$ minus the fraction $\left(1-\rho^{x}\right)\left(1-\rho_{t}^{n, \delta}\right)$ of bad matches that do not separate multiplied by the number of bad matches $n_{t}^{\delta}+q n_{t}^{g}$.

The next two equations determine the equilibrium number of matches and vacancies. Firms post vacancies up to the point where the marginal benefit of doing so equals the marginal cost $c$ :

$$
c=\frac{m_{t}}{v_{t}} F_{t}^{g}
$$

$F_{t}^{g}$ is the value today of filling a vacancy and $\frac{m_{t}}{v_{t}}$ is the likelihood that the vacancy is filled.

The following function determines the number of matches:

$$
m_{t}=\frac{u_{t} v_{t}}{\left(u^{L}+v^{L}\right) \frac{1}{L}}
$$

This function, introduced by den Haan et al. (2000), ensures that $\frac{m_{t}}{v_{t}}$ and $\frac{m_{t}}{u_{t}}$ are always between zero and one, a useful property for estimating the model. Therefore, I use this matching function instead of the more conventional Cobb-Douglas formulation. This matching function exhibits constant returns to scale and $m$ is increasing in $u$ and $v$. Moreover, $\frac{m}{v}$ and the finding rate, $\frac{m}{u}$, are decreasing in $v$ and $u$ respectively. This type of random matching function is meant to model frictions in the labor market. Unemployed workers cannot immediately find a job, but do so randomly with a probability less than one.

Lastly, next period's employment stocks are

$$
\begin{aligned}
& n_{t+1}^{g}=\left(1-\rho^{x}\right)\left(1-\rho_{t}^{n, g}\right)(1-q) n_{t}^{g}+m_{t} \\
& n_{t+1}^{\delta}=\left(1-\rho^{x}\right)\left(1-\rho_{t}^{n, \delta}\right)\left(n_{t}^{\delta}+q n_{t}^{g}\right)
\end{aligned}
$$




\subsection{Empirical Motivation for Vulnerable Jobs}

The two different types of jobs can be thought of as different areas of the labor market. Some areas are more productive than others due to the availability of resources, institutions, and the current industry mix. High-productivity areas can transition to low-productivity areas due to the obsolescence of technology or changes in the availability of resources. The assumption that all matches start out as good matches is an assumption that firms only create jobs in high productivity areas. The absence of on-the-job search in this model signifies that in order to find a more productive job workers have to leave their geographic areas, enduring at least a period of unemployment.

Jacobson et al. (1993) (JLS) find that workers experience wage losses before separation occurs. This fact is consistent with the model's assumption that separations come from matches that have had consistently low productivity. The finding that wage losses occur before separation is echoed in Hamermesh (1988). There is less evidence on the importance of mobility and job search. However, JLS show that workers who separate in areas with worse labor markets have substantially larger losses from unemployment. Therefore, workers have incentive to be mobile in unemployment and to search in labor markets different from their own. It is worth noting that my model is not completely consistent with the JLS evidence. My model, like the original MP model, assumes that when unemployed workers find a new job they are employed at the highest productivity level. JLS find substantial wages losses that persist with separated workers even onto future jobs.

\subsection{Empirical Motivation for Wage Rigidity}

Real-wage rigidity is an important feature of the model in this paper. As pointed out by Shimer (2005a), the standard Mortensen-Pissarides model does not generate sufficient volatility in unemployment and vacancies. Hall (2005a) notes that the model's amplification mechanisms are greatly improved by adding real wage rigidity. This is true even if the wage is allowed to adjust to avoid inefficient separations. Substantial real-wage rigidity 
moves the model towards paying the worker a wage that does not vary much with the state of aggregate productivity. As a result, the firm keeps most of the gains from aggregateproductivity increases and absorbs most of the losses of aggregate-productivity decreases. This mechanism makes the firm's recruiting incentives highly procyclical, generating variance in unemployment and vacancies through the finding rate. For my purposes, it is important to have a model that can generate volatility in unemployment and vacancies close to that in the data, hence the prominent role of real wage rigidity.

Beyond the empirical necessity, additional research points to the importance of real wage rigidity. Hall (2005a) argues that there is a social consensus as to what the fair wage is and that a sense of a fair wage may affect wage setting. Akerlof et al. (1996) and Bewley (1999) support this view as well. Falk et al. (2006) introduce minimum wages in experimental settings. They find introducing minimum wages raises reservations wages. Even after removing the minimum wage, the reservation wages remain higher than before. They argue that the minimum wage shapes what subjects consider a fair wage.

While the average wage's relative acyclicality is well known, the cyclicality of new hires' wages is currently an active research area. As noted by Pissarides (2009) and Haefke et al. (2008), in a sample of those who have begun work recently, wages are much more sensitive to unemployment or aggregate productivity than the average wage. This evidence would seem to cast doubt on the ability of wage rigidity to explain fluctuations in job-finding. However, as Gertler \& Trigari (2006) argue, these studies fail to control for changes in the type of job at which workers work. For example, if in recessions workers transition more from well paying jobs (e.g. manufacturing) to poorer paying jobs (e.g. retail), wages will be very sensitive to aggregate productivity. After controlling for job-specific characteristics, they find that wages of new hires are no more sensitive to the aggregate state of the economy than current employees. In my models there is only one type of job that workers can be hired into, therfore I take the Gertler and Triagari evidence as more relevant for evaluating the realism of the model. 
Table 1: Vulnerable Jobs Model Parameters

\begin{tabular}{lcc}
\hline \hline Calibrated & & \\
\hline Discount factor & $\beta$ & 0.99 \\
Aggregate productivity shock standard deviation & $\sigma^{\varepsilon}$ & 0.0091 \\
Productivity autoregressive parameter & $\varphi$ & 0.992 \\
Exogenous separation rate & $\rho^{\mathrm{x}}$ & 0.083 \\
Firm's bargaining share & $\pi$ & 0.5 \\
& & \\
Estimated & & \\
Flow value of unemployment & $\mathrm{b}$ & \\
Idiosyncratic productivity standard deviation (Good Job) & $\sigma^{z, g}$ & \\
Vacancy posting cost & $\mathrm{c}$ & \\
Matching function parameter & $\mathrm{L}$ & \\
Sticky wage weight & $\lambda$ & \\
Bad job transition probablity & $\mathrm{q}$ & \\
Bad job's productivity loss & $\delta$ & \\
Idiosyncratic productivity standard deviation (Bad Job) & $\sigma^{z, \delta}$ \\
& & \\
\end{tabular}

This table describes the parameters from the vulnerable jobs model and explains which variables are calibrated and which are estimated. It also gives the values of the calibrated parameters.

\section{Model Solution, Estimation, and Results}

\subsection{Model Solution}

I solve the model by calculating, numerically, the non-stochastic steady state. Then I log-linearize the dynamics around this steady state. To obtain the state space form of the model I use the programs of King \& Watson (2002). The steady state equations, along with the equations for the linearized dynamics, are in a web appendix. ${ }^{2}$

\subsection{Calibration}

Table one contains the parameters that are calibrated and those that are estimated. The discount factor in the model, $\beta$, is set to 0.99 . A period is set to one quarter.

The exogenous separation rate, following Fujita (2004), is set to $\rho^{x}=0.083$. In the data,

\footnotetext{
${ }^{2}$ http://people.brandeis.edu/ tortoric/Papers/WebAppendix.pdf
} 
the quarterly separation rate is 0.098 . Fujita (2004) calibrates the exogenous separation rate based on Topel (1990). Topel defines a displaced worker as one who has changed employers since the previous year because: 1.) the company went out of business, 2.) the worker was laid off or fired or 3.) the job was completed. Fujita equates endogenous separation $\left(\rho^{n}\right)$ with this type of separation. He then calculates the yearly probability of experiencing this type of displacement from Topel. The yearly probability is 0.064 , which implies a quarterly probability of 0.016 . Combining this statistic with the formula for the overall separation rate $0.098=s=\rho^{x}+\left(1-\rho^{x}\right) \rho^{n}$, Fujita obtains $\rho^{x}=0.083$.

Finally, the firm's Nash bargaining weight is set to $\pi=0.5$ (the value in Gertler \& Trigari (2006) and den Haan et al. (2000)). This choice is the most common in the literature and not very different from the recent estimate of Flinn (2006), who finds $\pi=0.597$. Robustness to the choice of $\rho^{x}$ and $\pi$ is shown in section five. Note that the choice of $\pi$ only determines the split in steady state. Real-wage rigidity induces variability in how the surplus is split over time. In high-productivity times the firm receives the majority of the surplus. In low productivity times the worker gets most of the surplus.

To calibrate the parameters of the productivity process I match the variance and the autocorrelation of labor-productivity in the data ${ }^{3}$. All other parameters are estimated by GMM or exogenously varied to study different scenarios.

\subsection{Estimation}

To estimate the parameters by the Generalized Method of Moments (GMM), I solve

$$
\widehat{\theta}=\arg \min g_{T}(\theta) W g_{T}(\theta)^{\prime}
$$

\footnotetext{
${ }^{3}$ Specifically I set $E_{t}\left[\operatorname{var}\left({\frac{y_{t}}{l_{t}}}^{h p}\right)-\operatorname{var}\left(\widehat{y}_{t}^{h p}\right)\right]=0$ and $E_{t}\left[\frac{\operatorname{cov}\left({\frac{y_{t}}{l_{t}}}^{h p},{\frac{y_{t-1}}{l_{t-1}}}^{h p}\right)-\operatorname{cov}\left(\widehat{y}_{t}^{h p}, \widehat{y}_{t-1}^{h p}\right)}{\operatorname{var}\left(\widehat{y}_{t}^{h p}\right)}\right]=0$ where ${\frac{y_{t}}{l_{t}}}^{h p}$ is HP filtered labor productivity in logarithms from Shimer (2005a)'s data and $\widehat{y}_{t}^{h p}$ is the model's prediction for HP filtered log deviation of productivity from its steady state.
} 
where $g_{T}(\theta)=E_{T}\left(u_{t}(\theta)\right)$. The vector $u_{t}(\theta)$ is the vector whose expectation is the difference between the moments in the data and those predicted by the model. The moments I use are: the variances of and covariances between unemployment, vacancies, finding rate, and separation rate. In addition I include the mean of the finding rate and separation rate. ${ }^{4}$

I use the two-step, efficient GMM procedure, first using the identity matrix as the weighting matrix and using the resulting parameters to calculate the Newey \& West (1987) estimator of the variance-covariance matrix:

$$
\widehat{S}=\sum_{j=-k}^{k}\left(\frac{k-|j|}{k}\right) \frac{1}{T} \sum_{t=1}^{T}\left(u_{t}-E_{t}\left(u_{t}\right)\right)\left(u_{t-j}-E_{t}\left(u_{t-j}\right)\right)^{\prime}
$$

In my estimation I set $k=5$. Then I use $\widehat{S}^{-1}$ as the second stage weighting matrix. Finally, the following formula is used for the standard errors ${ }^{5}$ :

$$
\begin{aligned}
\operatorname{Var}(\widehat{\theta}) & =\frac{1}{T}\left(d^{\prime} \widehat{S}^{-1} d\right)^{-1} d^{\prime} \widehat{S}^{-1}\left[S+d_{f}^{\prime} \Omega_{f} d_{f}\right] \widehat{S}^{-1} d\left(d^{\prime} \widehat{S}^{-1} d\right)^{-1} \\
d & =\frac{\partial g_{T}(\theta)}{\partial \theta} \quad \text { and } \quad d_{f}=\frac{\partial g_{T}(\theta)}{\partial \chi}
\end{aligned}
$$

Here $\chi$ is the vector of non-estimated parameters listed in Table 1. $\chi=\left\{\beta, \rho^{x}, \pi, \phi, \sigma^{\varepsilon}\right\}$. $\Omega_{f}=\operatorname{Var}(\chi)$. The appendix discusses estimation of $\Omega_{f}$. Note that for the case where the variance of the non-estimated parameters is assumed to be zero the formula reduces to the standard formula $\operatorname{Var}(\widehat{\theta})=\frac{1}{T}\left(d^{\prime} \widehat{S}^{-1} d\right)$. For all moments in the data I use the logarithm of HP filtered data. I compare these data moments to the moments of the HP filtered model variables in log deviations from steady state. See Burnside (1999) for the justification of this estimation strategy and the appendix of this paper for a description of Burnside's method for obtaining the log HP filtered moments of the model.

\footnotetext{
${ }^{4}$ Estimation of the constant separation rate model omits the covariances between the separation rate and the other variables.

${ }^{5}$ See Laibson et al. (2007) for a derivation.
} 


\subsection{Data}

The data come from Shimer (2005a). All data, except labor productivity, are quar-

terly averages of monthly series. Data begin in 1951 and end in 2003. Unemployment and labor-productivity data come from the Bureau of Labor Statistics (BLS). The series on vacancies comes from the Conference Board's Help Wanted advertisements series. Shimer (2005b) constructs series for the job-finding rates and job-separation rates from the BLS's Current Population Survey (CPS). All data are expressed in logarithms and HP filtered with a smoothing parameter $10^{5}$. Additionally, finding and separation rates are set to quarterly rates using the following formula: $x^{q}=1-\left(1-x^{m}\right)^{3}$. The likelihood of finding a job in a quarter is one minus the likelihood of not finding a job for three months.

\subsection{Vulnerable Jobs Model Results}

Table two, column labeled Model 1, contains the results from estimating the vulnerable jobs model. The model predicts a standard deviation of unemployement equal to 0.14 close to the 0.19 in the data. The model also almost exactly matches the observed standard deviation of the job-finding rate: the model predicts 0.059 , in the data it is 0.058 . The model predicts a standard deviation for the separation rate of 0.106 ; in the data it is 0.073. High-productivity jobs flow to the lower productivity state with a probability (q) of $6.2 \%$ per quarter. The lower productivity state $(\delta)$ is, on average, $25 \%$ less productive.

The model predicts all the correct signs for the correlation coefficients. The model's major shortcoming is its prediction that all the main variables should be very highly correlated. This is not, in fact, the case in the data, though all the correlation coefficients are greater (in absolute value) than 0.5 .

The estimated value for the worker's outside option, $b$, is 0.79 . This number is higher than $b=0.75$ which I take to be the upper end of the admissable values of $b$ based on the evidence of Costain \& Reiter (2003). To be certain that the vulnerable-jobs model can match the data moments when $b=0.75$, I re-estimate the model under this restriction (Table 
Table 2: Efficient Separation Variable Separation Rate (Vulnerable Jobs Model) Results

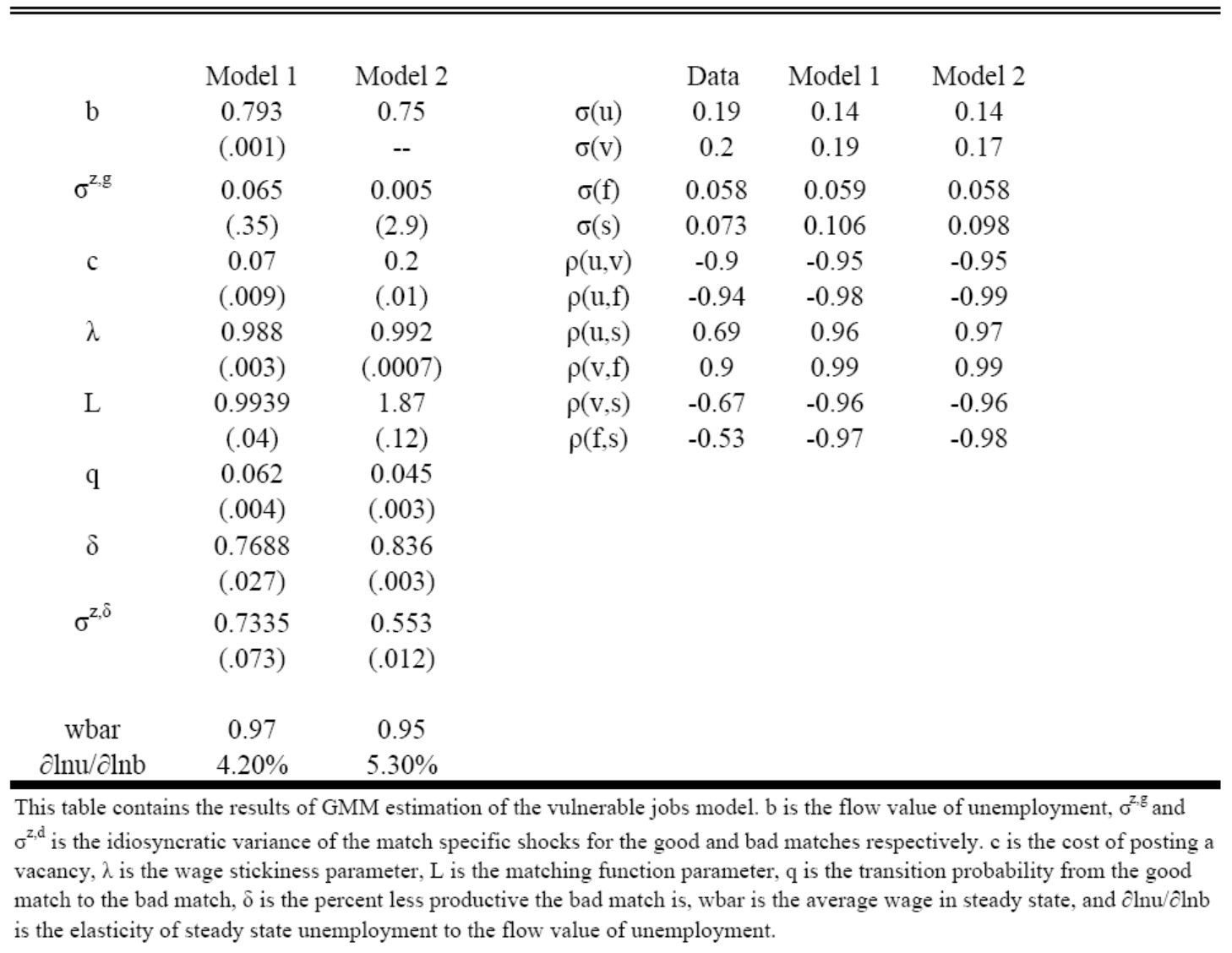


2, Column: Model 2). The predicted moments are similar to the unrestricted version; the biggest discrepancy comes in its prediction for the volatility of vacancies. The restricted model predicts a standard deviation of 0.17 while the unrestricted model predicts a standard deviation of 0.19 . In the data the standard deviation of vacancies is 0.2 .

Since the model has two jobs with differing productivity it may not be immediately clear how to express the outside option as a percent of the average value of unemployment. To facilitate this comparison the table reports the average wage in the economy. It is 0.97 for the model with $\mathrm{b}=0.79$ and 0.95 for the model with $\mathrm{b}=0.75$. I also report the elasticity of unemployment to changes in (b) the flow value of unemployment. They are 4.3 and 5.3 respectively, a substantial improvement over the elasticity of 14 implied by the Hagedorn \& Manovskii (2006) $(\mathrm{b}=.96)$ calibration.

\section{Constant Separation Rate Model}

\subsection{Theoretical Model}

Can the model explain the volatility of unemployment without a variable separation rate? I find that it cannot. I remove the permanent shocks from the vulnerable jobs modeltherefore removing any incentive to separate- and then re-estimate the model. This allows me to find the best fitting model with a constant separation rate. I therefore find that no calibration of the constant separation rate model satisfactorily explains the data by searching over the entire parameter space.

The equations for the constant separation rate model are obtained by taking the equations from the vulnerable jobs model and omitting the equations that describe the bad job. Then,

in the remaining equations one sets $n^{\delta}, \rho^{n, \delta}$ and $q=0$. A full description of the model equations is available in the web appendix mentioned in section 3.1. 
Table 3: Parameters in the Constant Separation Rate Model

\begin{tabular}{lcc}
\hline \hline Calibrated & $\beta$ & 0.99 \\
Discount factor & $\sigma^{\varepsilon}$ & 0.0091 \\
Aggregate productivity shock standard deviation & $\varphi$ & 0.992 \\
Productivity autoregressive parameter & $\rho^{\mathrm{x}}$ & 0.083 \\
Exogenous separation rate & $\pi$ & 0.5 \\
Firm's bargaining share & $\mathrm{b}$ & 0.75 \\
Flow value of unemployment & & \\
& & \\
Estimated & $\sigma^{z}$ \\
Idiosyncratic productivity standard deviation & $\mathrm{c}$ \\
Vacancy posting cost & $\mathrm{L}$ \\
Matching function parameter & $\lambda$ \\
Sticky wage weight & \\
& \\
\hline This table describes the parameters from the constant separation model and explains \\
which variables are calibrated and which are estimated. It also gives the values of the \\
calibrated parameters.
\end{tabular}

\subsection{Constant Separation Results}

Table three gives the parameters of the constant, efficient separation model and table four presents the results from estimating the constant separation rate model. I set $b$ (the flow value of unemployment) equal to $0.75 .{ }^{6}$ I then estimate the remaining parameters $\sigma^{z}$ (the standard deviation of the idiosyncratic shock), $c$ (the cost of posting a vacancy), $\lambda$ (the weight on the wage norm), and $L$ (the matching function parameter). The estimation drives $\lambda$ to 1 ; a fixed wage is necessary to generate enough volatility in unemployment. Thus I set $\lambda=0.99999$ and re-estimate the model.

First, note that the model generates no volatility in the separation rate. The standard deviation of the separation rate is essentially zero. Worker outside options are low enough that without permanent productivity shocks the value of the job never falls below the value of the workers outside option.

The key observation in this section is that despite searching over the entire parameter

\footnotetext{
${ }^{6}$ Estimation of $b$ drives the parameter to 1 . Based on the evidence in section 1, I reject models with near indifference between work and unemployment. Therefore, I calibrate $b$ based on the evidence of Costain \& Reiter (2003).
} 
Table 4: Constant Separation Rate Model Results

\begin{tabular}{|c|c|c|c|c|}
\hline \multirow{3}{*}{$\mathrm{b}$} & Constant Sep Rate & & Data & Constant Sep Rate \\
\hline & 0.75 & $\sigma(\mathrm{u})$ & 0.19 & 0.09 \\
\hline & --- & $\sigma(\mathrm{v})$ & 0.2 & 0.3 \\
\hline \multirow[t]{2}{*}{$\sigma^{z}$} & 0.32 & $\sigma(f)$ & 0.058 & 0.1 \\
\hline & $(.0000008)$ & $\rho(u, v)$ & -0.89 & -0.83 \\
\hline \multirow[t]{2}{*}{$\mathrm{c}$} & 0.67 & $\rho(u, f)$ & -0.95 & -0.9 \\
\hline & $(.000004)$ & $\rho(v, f)$ & 0.9 & 0.99 \\
\hline \multirow[t]{2}{*}{$\lambda$} & 0.99999 & $\sigma(\mathrm{s})$ & 0.073 & $<.0001$ \\
\hline & --- & & & $4.1 \times 10^{-13}$ \\
\hline $\mathrm{L}$ & $\begin{array}{c}202.68 \\
(5.7)\end{array}$ & & & \\
\hline \multirow{2}{*}{$\begin{array}{c}\text { wbar } \\
\partial \ln u / \partial \ln b\end{array}$} & 0.98 & & & \\
\hline & $0.01 \%$ & & & \\
\hline \multicolumn{5}{|c|}{$\begin{array}{l}\text { This table contains the results of GMM estimation of the model in section } 4 \text {. This model, when } \mathrm{b} \text { is set } \\
\text { to } 0.75 \text {, is the constant separation rate version of the vulnerable jobs model. The estimation imposes } \mathrm{b} \\
\text { (the flow value of leisure) equal to } .75 . \sigma^{z} \text { is the idiosyncratic shock standard deviation, } \mathrm{c} \text { is the } \\
\text { vacancy cost, } \lambda \text { is the sticky wage weight and } \mathrm{L} \text { is the matching function parameter. Wbar is the } \\
\text { average wage in steady state and } \partial \ln u / \partial \ln b \text { is the elasticity of steady state unemployment to the flow } \\
\text { value of unemployment. }\end{array}$} \\
\hline
\end{tabular}

space the overall fit of the model is poor. Since variation in the finding rate is the only channel generating unemployment volatility, the model predicts finding rate volatility and a vacancy volatility that is much higher than in the data. The model predicts that the standard deviation of the finding rate should be 0.1 vs. 0.058 in the data. Even with a finding rate almost twice as volatile as the data, the model underestimates the volatility of unemployment. The model predicts that unemployment volatility should be 0.09 versus the 0.19 found in the data.

So then, do models of unemployment fluctuations need separation rate volatility? The answer is a resounding yes. Firstly, even the best fitting model without separation rate volatility, found by searching over the whole parameter space, does not explain the volatility of unemployment and even does a poor job predicting the volatility of the job-finding rate. Secondly, as shown in the previous section, adding in separation rate volatility substantially improves the ability of the model to predict the volatilities of all the main variables: unemployment rate, vacancies, job-finding rate and the job-separation rate. 
One might be concerned that the transition from two jobs with differing productivity to one job has effects on dynamics in addition to its effect on the separation rate. To alleviate these concerns I report the average wage for this version of the model. It is 0.98 versus 0.97 for the previous model. Therefore, going from two jobs to one job does not substantially affect the average value of work.

Another concern may be my use of only technology shocks in estimation. I make this choice to be consistent with the literature and to keep clear the mechanism driving the results. The mechanism is simple: the finding rate is not volatile enough for a model to explain the unemployment volatility solely through that channel. This result is most surely robust to the inclusion of additional shocks. These shocks may raise the volatility of unemployment, but in a constant separation rate model they must do it through the job-finding rate leading to too much volatility in job-finding. Similarly, the reliance on wage rigidity can be thought of as a simple stand in for other mechanisms that may increase finding rate volatility. While additional mechanisms (for example variation in the cost of vacancy posting) may raise the volatility of unemployment, they would do so by increasing the volatility of the job finding rate and leading to too much finding rate volatility.

\section{Robustness}

\subsection{Non-Estimated Parameters}

This section explores the robustness of model dynamics to changes in the non-estimated parameters. I confirm that I can replicate the model's predictions for the moments under different assumptions about the non-estimated parameters. I focus on the model's dynamics under different assumptions for $\rho^{x}$ and $\pi$. I re-calculate the moments of each model, varying these parameters using the estimated values for the other parameters. The benchmark value is $\rho^{x}=0.083$. I recalculate the moments setting $\rho^{x}=0.1$ and $\rho^{x}=0.064$. For these calibrations I keep $\pi=0.5$. Next, I keep $\rho^{x}=0.083$ and set $\pi=0.4$ and then $\pi=0.6$. 
Table 5: Robustness to choice of $\rho^{\mathrm{x}}$ and $\pi$

\begin{tabular}{|c|c|c|c|c|c|c|c|c|c|c|}
\hline Vulnerable Jobs Model & $\sigma(\mathbf{u})$ & $\sigma(\mathrm{v})$ & $\sigma(f)$ & $\sigma(\mathrm{s})$ & $\rho(u, v)$ & $\rho(u, f)$ & $\rho(u, s)$ & $\rho(v, f)$ & $\rho(\mathbf{v}, \mathbf{s})$ & $\rho(\mathbf{f}, \mathbf{s})$ \\
\hline$\rho^{x}=.083, \pi=.5$ & 0.14 & 0.19 & 0.059 & 0.106 & -0.95 & -0.98 & 0.96 & 0.99 & -0.96 & -0.97 \\
\hline$\rho^{x}=.1, \pi=.5$ & 0.11 & 0.22 & 0.064 & 0.066 & -0.95 & -0.98 & 0.93 & 0.99 & -0.97 & -0.97 \\
\hline$\rho^{\mathrm{x}}=.064, \pi=.5$ & 0.14 & 0.23 & 0.073 & 0.094 & -0.95 & -0.98 & 0.93 & 0.99 & -0.93 & -0.94 \\
\hline$\rho^{\mathrm{x}}=.083, \pi=.6$ & 0.16 & 0.16 & 0.049 & 0.125 & -0.95 & -0.99 & 0.98 & 0.99 & -0.95 & -0.98 \\
\hline$\rho^{\mathrm{x}}=.083, \pi=.4$ & 0.14 & 0.2 & 0.064 & 0.1 & -0.95 & -0.98 & 0.96 & 0.99 & -0.96 & -0.97 \\
\hline Vulnerable Jobs Model $(b=.75)$ & $\sigma(\mathbf{u})$ & $\sigma(v)$ & $\sigma(f)$ & $\sigma(\mathrm{s})$ & $\rho(u, v)$ & $\boldsymbol{\rho}(\mathbf{u}, \mathbf{f})$ & $\rho(u, s)$ & $\rho(v, f)$ & $\rho(v, s)$ & $\rho(\mathbf{f}, \mathbf{s})$ \\
\hline$\rho^{\mathrm{x}}=.083, \pi=.5$ & 0.14 & 0.17 & 0.058 & 0.098 & -0.95 & -0.99 & 0.97 & 0.99 & -0.96 & -0.98 \\
\hline$\rho^{\mathrm{x}}=.1, \pi=.5$ & 0.11 & 0.17 & 0.056 & 0.072 & -0.95 & -0.98 & 0.96 & 0.99 & -0.98 & -0.98 \\
\hline$\rho^{\mathrm{x}}=.064, \pi=.5$ & 0.18 & 0.14 & 0.053 & 0.15 & -0.93 & -0.99 & 0.98 & 0.98 & -0.93 & -0.97 \\
\hline$\rho^{x}=.083, \pi=.6$ & 0.11 & 0.14 & 0.045 & 0.083 & -0.95 & -0.98 & 0.96 & 0.99 & -0.96 & -0.98 \\
\hline$\rho^{x}=.083, \pi=.4$ & 0.14 & 0.18 & 0.067 & 0.091 & -0.95 & -0.98 & 0.96 & 0.99 & -0.96 & -0.98 \\
\hline Constant Separation Rate Model & $\sigma(\mathbf{u})$ & $\sigma(\mathrm{v})$ & $\sigma(f)$ & $\sigma(\mathrm{s})$ & $\rho(u, v)$ & $\rho(u, f)$ & $\rho(v, f)$ & & & \\
\hline$\rho^{\mathrm{x}}=.083, \pi=.5$ & 0.09 & 0.3 & 0.1 & $<.0001$ & -0.83 & -0.9 & 0.99 & & & \\
\hline$\rho^{x}=.1, \pi=.5$ & 0.095 & 0.26 & 0.11 & $<.0001$ & -0.83 & -0.9 & 0.99 & & & \\
\hline$\rho^{\mathrm{x}}=.064, \pi=.5$ & 0.11 & 0.34 & 0.12 & $<.0001$ & -0.83 & -0.9 & 0.99 & & & \\
\hline$\rho^{x}=.083, \pi=.6$ & 0.08 & 0.29 & 0.09 & $<.0001$ & -0.83 & -0.9 & 0.99 & & & \\
\hline$\rho^{\mathrm{x}}=.083, \pi=.4$ & 0.08 & 0.3 & 0.09 & $<.0001$ & -0.83 & -0.9 & 0.99 & & & \\
\hline
\end{tabular}

$\rho^{\mathrm{x}}$ is the exogenous separation rate, $\pi$ is the firm's share of the surplus

Often the moments of the model do not change at all. When the moments do change, I can easily restore them with reasonable changes in the estimated parameters. For example, lowering $\rho^{x}$ increases the value of the worker to a firm, which affects the dynamics by increasing the finding rate. Increasing $c$, the cost of posting a vacancy, restores the original dynamics. Similarly, changes in $b$ can offset increases in the firm's share of the surplus. ${ }^{7}$

The results are in table five. It is easy to replicate the model's predictions under different assumptions about the non-estimated parameters. The conclusions are the same. The vulnerable jobs model generates endogenous separation and fits the data fairly well. The constant separation rate continues to fit the data poorly.

\subsection{Monthly Results}

I calibrated my model to quarterly data. As a result, I adjust the Shimer data so that the finding rate is expressed as a quarterly rate and calculate the standard deviation of this variable. Shimer, on the other hand, stresses the standard deviation of the quarterly average

\footnotetext{
${ }^{7}$ The final section of the appendix documents all parameter changes.
} 


\begin{tabular}{cccc}
\hline \hline & Data & Variable Separation & Constant Separation \\
$\sigma(\mathrm{u})$ & 0.128 & 0.104 & 0.11 \\
$\sigma(\mathrm{v})$ & 0.141 & 0.106 & 0.19 \\
$\sigma(\mathrm{f})$ & 0.086 & 0.088 & 0.12 \\
$\rho(\mathrm{u}, \mathrm{v})$ & -0.9 & -0.67 & -0.6 \\
$\rho(\mathrm{u}, \mathrm{f})$ & -0.78 & -0.91 & -0.83 \\
$\rho(\mathrm{v}, \mathrm{f})$ & 0.81 & 0.92 & 0.95 \\
\hline
\end{tabular}

This table gives the results from re-estimating the model after calibrating it to monthly data.

of the monthly rate. Since this is an arithmetic average, not a geometric average, the finding rate variance changes substantially under the two methods. Given that the monthly finding rate is high, about $40 \%$, the quarterly finding rate is close to one (about $80 \%$ ) and is therefore less variable then the monthly rate.

In this paper, I conclude that the separation rate helps the model better fit the unemployment fluctuations data. I now confirm that this result is not driven by the quarterly calibration. I re-estimate the models, calibrating the model to the monthly data. To smooth the series, I follow Ravn \& Uhlig (1997) and use a smoothing parameter of 129, 600 for the monthly data. ${ }^{8}$ The results are in Table 6 . The higher monthly finding rate variance helps the constant separation rate model fit the data better. However, it still overestimate the variance of vacancies by about $25 \%$ and the variance of the finding rate by about $50 \%$. In contrast, the endogenous separation rate model generates the same amount of unemployment volatility and does not overestimate the volatility of vacancies and the finding rate.

\subsection{On-the-job search}

For the constant separation rate model explored in this paper, on-the-job search is irrelevant, since there is no job heterogeneity lasting more than one period. However, the vulnerable jobs model does have persistent differences in job type. As a result, adding onthe-job search may change the dynamics of this model. While a full model of on-the-job

\footnotetext{
${ }^{8}$ Using this parameter the standard deviation of unemployment falls when compared to the quarterly data. This is because Shimer uses an extremely high smoothing parameter $(100,000)$ for quarterly data.
} 
search is beyond the scope of this paper, one can speculate about what would happen if onthe-job search were added. On-the-job search will raise the value of the bad job to the worker, lowering the rate of separation from this job. For small amounts of on-the-job search, this increased value of the job could be offset by lowering $\delta$ (the bad job's productivity fraction). Therefore, the results are most likely robust to the inclusion of on-the-job search.

\section{Conclusion}

Current research evaluating the Mortensen-Pissarides model can be broadly placed into two categories. One set of models uses wage rigidity to create substantial volatility in the job-finding rate, but assumes constant separation rates. Another set of models allows for endogenous separation but omits wage rigidity and does not generate sufficient volatility in the job-finding rate. As a result, neither set of models is equipped to fully evaluate the importance of separation rate volatility in explaining unemployment fluctuations. In this paper, I estimate a version of the MP model with endogenous separation and wage rigidity. The model is consistent with both the volatility of the job-finding rate and the job-separation rate. I show that an estimated version of the model where the job-separation rate is constant fails to explain the volatility of unemployment and greatly overestimates the volatility of the finding rate. Job separation rate volatility then is necessary to explain unemployment fluctuations.

There were two key shortcomings of the model. First, it predicted that unemployment, vacancies, the job-finding rate and the job-separation rate are almost perfectly correlated. In fact, while the correlations are high in the data, they are far from one. Allowing additional shocks may reduce this correlation. Since I solve the model by linearizing around the steady state, it is possible to add additional shocks without losing tractability. Second, the models

implied a fairly rigid wage. This result suggests that additional mechanisms in addition to wage rigidity may be needed to better match data on average wage volatility. 


\section{References}

Akerlof, George, Dickens, William T., \& Perry, George. 1996. The macroeconomics of low inflation. Brookings papers on economic activity, 0(1), 1-59.

Bewley, Truman. 1999. Why wages don't fall during a recssions. Cambridge MA: Harvard University Press.

Burnside, Craig. 1999. Real business cycle models: Linear approximation and gmm estimation. Mimeo world bank, May.

Costain, James S., \& Reiter, Michael. 2003. Business cycles, unemployment insurance, and the calibration of matching models. Department of economics and business, universitat pompeu fabra working paper, June.

den Haan, Wouter J., Ramey, Garey, \& Watson, Joel. 2000. Job destruction and propagation of shocks. American economic review, 90(3), 482-498.

Elsby, Michael W., Michaels, Ryan, \& Solon, Gary. 2007. The ins and outs of cyclical unemployment. National bureau of economic research working paper 12853, Jan.

Falk, Armin, Fehr, Ernst, \& Zehnder, Christian. 2006. The behavioral effects of minimum wages. The quarterly journal of economics, NOvember, 1347-1381.

Flinn, Christopher J. 2006. Minimum wage effects on labor market outcomes under search, matching, and endogenous contact rates. Econometrica, 74(4), 1013-1062.

Fujita, Shigeru. 2004. Vacancy persistence. Federal reserve bank of philadelphia working paper, October.

Gertler, Mark, \& Trigari, Antonella. 2006. Unemployment fluctuations with staggered nash wage bargaining. National bureau of economic research, working paper 12498, Aug.

Haefke, Christian, Sonntag, Marcus, \& vam Rens, Thijs. 2008. Wage rigidity and job creation. Mimeo.

Hagedorn, Marcus, \& Manovskit, Iourit. 2006. The cyclical behavior of equilibrium unemployment and vacancies revisited. University of chicago mimeo, April.

Hall, Robert, \& Milgrom, Paul. 2008. The limited influence of employment on the wage bargain. American economic review, 98, 1653-74.

Hall, Robert E. 2005a. Employment fluctuations with equilibrium wage stickiness. American economic review, 95(1), 50-65.

Hall, Robert E. 2005b. Job loss, job finding, and unemployment in the u.s. economy over the past fifty years. National bureau of economic research, macroeconomics annual, Oct. 
Hamermesh, Daniel S. 1988. Plant closings, labor demand and the value of the firm. Review of economics and statistics, Nov., 580-586.

Jacobson, Louis S, Lalonde, Robert J, \& Sullivan, Daniel G. 1993. Earnings losses of displaced workers. American economic review, 83(4), 685-709.

King, Robert G., \& Rebelo, Sergio T. 1993. Low frequency filtering and real business cycles. Journal of economic dynamics and control, 17(1-2), 207-231.

King, Robert G, \& Watson, Mark W. 2002. System reduction and solution algorithms for singular linear difference systems under rational expectations. Computational economics, 20(1-2), 57-86.

Laibson, David, Repetto, Andrea, \& Tobacam, Jeremy. 2007. Estimating discount functions with consumption choices over the lifecycle. Harvard department of economics working paper.

Menzio, Guido, \& Shi, Shouyong. 2009. Endogenous vs. exogenous separation. Penn institute for economic research mimeo, February.

Mortensen, Dale T, \& Pissarides, Christopher A. 1994. Job creation and job destruction in the theory of unemployment. Review of economic studies, 61(3), 397-415.

Newey, Whitney K, \& West, Kenneth D. 1987. A simple, positive semi-definite, heteroskedasticity and autocorrelation consistent covariance matrix. Econometrica, 55(3), 703-08.

Pissarides, Christopher. 2009. The unemployment volatility puzzle: is wage stickiness the answer. Econometrica, 77, 1339-1369.

Ramey, Garey. 2008. Endogenous vs. exogenous separation. mimeo, October.

Ravn, M.O., \& Uhlig, H. 1997. On adjusting the hp-filter for the frequency of observations. Tilburg university, center for economic research discussion paper.

Shimer, Robert. 2005a. The cyclical behavior of equilibrium unemployment and vacancies. American economic review, 95(1), 25-49.

Shimer, Robert. 2005b. Reassessing the ins and outs of unemployment. University of chicago, mimeo, January.

Topel, Robert. 1990. Specific capital and unemployment: Measuring the costs and consequences of job loss. Carnegie-rochester conference series on public policy, 33, 181-214. 


\section{A Moment Calculation}

To calculate the Hodrick-Prescott filtered moments of the linearized model I follow the methodology of Burnside (1999). Using the programs provided by King \& Watson (2002), I can obtain the model in state space form

$$
\begin{aligned}
s_{t+1} & =M s_{t}+\varepsilon_{t} \\
x_{t} & =H s_{t}
\end{aligned}
$$

where $s$ contains the predetermined variables and the exogenous variables and $x$ contains the jump variables.

Burnside shows

$$
\begin{aligned}
E\left[x_{t}^{h p} x_{t-i}^{h p \prime}\right] \approx & \sum_{j=-N+i}^{N} b_{j} b_{j-1} \Gamma_{o}+\sum_{k=1}^{i} \sum_{j=-N+i-k}^{N} b_{j} b_{j+k-i} \Gamma_{k}+\sum_{k=1}^{i} \sum_{j=-N+i-k}^{N} b_{j} b_{j-k-i} \Gamma_{k}^{\prime}(25) \\
& +\sum_{k=i+1}^{M} \sum_{j=-N-i+k}^{N} b_{j} b_{j+i-k} \Gamma_{k}+\sum_{k=i+1}^{M} \sum_{j=-N+k-i}^{N} b_{j} b_{j-k-i} \Gamma_{k}^{\prime}
\end{aligned}
$$

where $N \gg M \gg i$.

To calculate this formula we must first decompose $M=V D V^{-1}$ where $D$ is a diagonal matrix with the eigenvalues of $M$ on the diagonal and $V$ contains the corresponding eigen vectors. Then we can write

$$
\widetilde{\Gamma}_{0, i, j}=\frac{1}{1-d_{i} d_{j}} \widetilde{\Sigma}_{i j}
$$

where $\widetilde{\Sigma}_{i j}=V^{-1}\left(\begin{array}{cc}0 & 0 \\ 0 & \sigma_{\varepsilon}^{2}\end{array}\right)\left(V^{-1}\right)^{\prime}$. Then $\Gamma_{o}^{s}=V \widetilde{\Gamma}_{0} V^{\prime}$ and $\Gamma_{o}=H \Gamma_{o}^{s} H^{\prime}=E\left[x_{t} x_{t}^{\prime}\right]$ and $\Gamma_{k}=H M^{k} \Gamma_{o}^{s} H^{\prime}=E\left[x_{t} x_{t-i}^{\prime}\right]$.

Finally, since I use a smoothing parameter of $10^{5}$ to match Shimer (2005a), my $b_{j}$ depart from Burnside. According to King \& Rebelo (1993), the correct $b_{j}=r^{j} a_{1} \cos (|m| j)+$ $a_{2} \sin (|m| j)$ where $r=.961, a_{1}=.0199,|m|=.0398$, and $a_{2}=.0199$. 


\section{B Covariance Matrix of Non-Estimated Parameters}

Let $\chi=\left\{\beta, \rho^{x}, \pi, \phi, \sigma^{\varepsilon}\right\}$ and $\Omega_{f}=\operatorname{Var}(\chi)$. I assume that all parameters are independent of each other except for $\phi$ and $\sigma^{\varepsilon}$, the $\operatorname{AR}(1)$ coefficient and the standard deviation of the exogenous productivity shock. Therefore all off-diagonal elements of $\Omega_{f}$ are zero except for the term for the covariance between $\phi$ and $\sigma^{\varepsilon}$. To estimate the $\operatorname{var}(\beta) \mathrm{I}$ assume $\beta=$ $E\left[1 /\left(1+r_{t}\right)\right]$ where $r_{t}$ is the real interest rate on the 3 -month t-bill. Using a Newey-West estimator of this mean I find a standard error for $\beta$ equal to 0.002 . This estimate was the maximum over several lag choices for the Newey-West estimator.

To estimate $\operatorname{var}\left(\rho^{x}\right)$, first note that given the overall mean of the separation rate one can write $0.098=s=\rho^{x}+\left(1-\rho^{x}\right) \rho^{n}$ and $\rho^{x}=\frac{.098-\rho^{n}}{1-\rho^{n}}$. Topel (1990), in a sample of about 23, 300 workers from the Panel Study of Income Dynamics (PSID), finds that the average yearly endogenous separation rate is about $6.4 \%$. Hence, the estimate of the yearly endogenous separation rate is:

$$
\rho^{y}=\frac{1}{23000} \sum X_{i}
$$

where $X_{i}=0$ with probability 0.936 and 1 with probability 0.064 . Assuming the $X_{i}^{\prime} s$ are independent, and given the variance of a binary variable, we have $\operatorname{var}\left(\rho^{y}\right)=\frac{1}{23000}(.936)(.064)$. We can write the quarterly separation rate as $\rho^{n}=1-\left(1-\rho^{y}\right)^{\frac{1}{4}}$. Applying the delta method, the approximation that if $y=f(x)$ then $\operatorname{var}(y) \approx\left[f^{\prime}(x)\right]^{2} \operatorname{var}(x)$, we have $\operatorname{var}\left(\rho^{n}\right)=$ $\left[\frac{1}{4}\left(1-\rho^{y}\right)^{\frac{-3}{4}}\right]^{2} \operatorname{var}\left(\rho^{y}\right)$. Finally, $\rho^{x}=\frac{.098-\rho^{n}}{1-\rho^{n}}$ gives $\operatorname{var}\left(\rho^{x}\right)=\left[\frac{-1}{1-\rho^{n}}+\frac{.098-\rho^{n}}{\left(1-\rho^{n}\right)^{2}}\right]^{2} \operatorname{var}\left(\rho^{n}\right)$. Evaluating this formula yields a standard error for $\rho^{x}=0.00039$.

There are few estimates for $\pi$, the firm's bargaining share. I take the standard error of $\pi$ from Flinn (2006) who finds $\pi=0.597^{9}$ with a standard error of 0.003 . To be consistent with the literature, I take $\pi=0.5$, but show my results are robust to Flinn's estimate in the robustness section.

Finally, as mentioned in the text, $\phi$ and $\sigma^{\varepsilon}$ the $\operatorname{AR}(1)$ coefficient and the standard

\footnotetext{
${ }^{9}$ Flinn estimates the worker's bargaining share which is $1-\pi$. He finds this value to be 0.403 .
} 
deviation of the exogenous productivity process are estimated by matching the variance and autocovariance of US labor productivity. The results of this GMM estimation yield a standard error for $\phi=0.07$ and a standard error for $\sigma^{\varepsilon}=0.0092$.

\section{Parameter Changes For Robustness Table}

Many rows do not change. These are rows: $1,2,3,6,7,8,10,11,12$. For row 4 , I increase $b$ to 0.6 . For row 5 , I lower $b$ to 0.1 . For row $9, \mathrm{I}$ increase $b$ to 0.955 . For row $13, \mathrm{I}$ decrease $\sigma^{\delta}$ to 0.72 . For row 14 , I increase $b$ to 0.81 . For row 15 , I decrease $b$ to 0.77 . 